\section{Case Reports in Ophthalmology}

\title{
Multiquadrant Subtenon Triamcinolone Injection for Acute Corneal Graft Rejection: A Case Report
}

\author{
Sunali Goyal Sami H. Uwaydat \\ Department of Ophthalmology, University of Arkansas for Medical Sciences, Little \\ Rock, AR, USA
}

\section{Keywords}

Cornea $\cdot$ Graft survival $\cdot$ Rejection $\cdot$ Corticosteroids

\begin{abstract}
Background: We report a case of reversal of an acute corneal graft rejection following multiquadrant subtenon triamcinolone injection. Case Presentation: A 19-year-old woman who had acute corneal graft rejection failed to show resolution of the graft rejection after standard treatment with systemic, intravenous, and topical steroids. The graft rejection, however, responded to injection of triamcinolone in multiple subtenon quadrants. Conclusions: For corneal graft rejection, multiquadrant subtenon triamcinolone injections may be a safe adjunct to systemic treatment.

\section{Background}

Immunological rejection of donor graft is the main cause of corneal transplant failure. The reported incidence of corneal graft rejection in different studies varies from 2.3 to $68 \%$ $[1,2]$. Overall, $30 \%$ of patients receiving transplanted corneas experience at least one episode of immune rejection, and about $5-7 \%$ of these episodes lead to eventual graft failure 


\section{Case Reports in Ophthalmology} \begin{tabular}{l|l}
\hline DOI: 10.1159/000477202 & $\begin{array}{l}\text { C 2017 The Author(s). Published by S. Karger AG, Basel } \\
\text { www.karger.com/cop }\end{array}$
\end{tabular}

Goyal and Uwaydat: Multiquadrant Subtenon Triamcinolone Injection for Acute Corneal Graft Rejection: A Case Report

[3-5]. Here we describe a case of acute corneal graft rejection that was successfully reversed by subtenon injection of triamcinolone in multiple quadrants.

\section{Case Presentation}

The patient was a 19-year-old African American woman who underwent uncomplicated full-thickness-penetrating keratoplasty in her right eye (OD) for advanced keratoconus. One week after surgery, she sustained a blunt trauma to OD that resulted in graft dehiscence from 3 to 5 o'clock, which was repaired surgically. Postoperatively, she received a topical steroid (prednisolone) 4 times a day tapered to 3 times a day at 3 months. Four months after surgery, her uncorrected vision was 20/60 in OD, with $6 \mathrm{dpt}$ of against-the-rule astigmatism. Two corneal sutures were removed with the guidance of topography. Four days later, the patient presented with redness, irritation, and sudden decrease in vision in OD to count fingers at 2 feet with intraocular pressure (IOP) of $11 \mathrm{~mm} \mathrm{Hg}$. Corneal examination showed diffuse haziness with stromal edema, Descemet membrane folds, and an incomplete Khodadoust line (Fig. 1). A diagnosis of acute corneal rejection was made. Intravenous pulse methylprednisolone (Solu-Medrol), $1 \mathrm{~g}$ daily for 3 days, was initiated, in addition to an hourly topical steroid (prednisolone). At 3 days after initiation of treatment, the patient was seen to have progression of the Khodadoust line and no improvement in graft rejection. At that point, a $1-\mathrm{mL}$ subtenon injection of $40 \mathrm{mg} / \mathrm{mL}$ of triamcinolone was placed in the superotemporal quadrant. The patient was asked to continue topical steroid drops and was started on oral prednisone, $60 \mathrm{mg} /$ day. Seen a week later, she showed improvement in vision to 20/80 in OD, although it was fuzzy according to the patient. There was a remarkable clearance of corneal edema and improved clarity in the superior half of the graft, with the inferior half remaining hazy (Fig. 2). IOP was $16 \mathrm{~mm} \mathrm{Hg}$. The patient was observed for another week with no further improvement. On the basis of the response to the initial subtenon triamcinolone injection, she received additional injections of $0.5 \mathrm{~mL}$ of triamcinolone $(40 \mathrm{mg} / \mathrm{mL})$ in the inferonasal and inferotemporal quadrants. Four days later, the corneal graft rejection had completely resolved, with no keratic precipitates and with complete resolution of corneal edema and haze (Fig. 3). Her vision improved to 20/50, and IOP remained stable at $14 \mathrm{~mm} \mathrm{Hg}$. Topical prednisolone was decreased to 8 times a day for 2 weeks and subsequently to 4 times a day. Oral prednisone was tapered to stop. At her last follow-up, 5 months after the injections, the corneal graft remained clear.

\section{Discussion and Conclusions}

Corneal graft rejection can present with sudden decline in vision, corneal edema, corneal haze, and keratic precipitates $[6,7]$. The rate of reversibility after acute corneal rejection ranges from 50 to $94 \%$, depending on time between onset and treatment, previous rejection episodes, graft size, and graft vascularity, among other factors [8].

Corticosteroids, administered through topical, periocular, oral, or intravenous routes, remain the mainstay of treatment for corneal graft rejection [1]. Intravenous pulse methylprednisolone (500-1,000 mg for 3 days) has been thought to reset the immune system and may be associated with superior graft survival when administered within the first week of the rejection episode [9]. Subconjunctival or posterior subtenon triamcinolone injections, along with topical steroids, have been considered valid alternatives in the treatment 
Goyal and Uwaydat: Multiquadrant Subtenon Triamcinolone Injection for Acute Corneal Graft Rejection: A Case Report

of endothelial rejection [10]. In this case, after no improvement in the signs of graft rejection was noted with intravenous pulse methylprednisolone treatment, in addition to an hourly topical steroid, a subtenon triamcinolone injection in the superotemporal quadrant produced significant clearing in the superior half of the cornea on follow-up 1 week later. With no further improvement after another week of observation, subtenon injections of triamcinolone were given in the inferonasal and the inferotemporal quadrants, with clearing of the inferior half of the cornea 3 days later and complete resolution of all signs of endothelial rejection.

Various animal studies have shown that subtenon and subconjunctival steroid injections lead to diffusion of the drug both anteriorly into the aqueous and posteriorly into the vitreous [11-13]. Triamcinolone injected in the subtenon space can reach the intraocular structures within $3 \mathrm{~h}$, with the highest concentrations found in the retinal pigment epithelium/choroid followed by the retina, and to a much lesser extent in the vitreous and anterior chamber [11-13]. Given that the mechanism of corneal graft rejection involves effector cells from the perilimbal circulation, the effect of subtenon triamcinolone in suppressing corneal graft rejection is likely due to its superficial diffusion to the perilimbal space rather than to its intraocular penetration (the anterior chamber has the lowest concentration). In our patient, the rapid resolution of the signs of corneal rejection closer to the injection site, with persistence of these signs opposite the injection site, supports this hypothesis. Subsequent resolution of signs of rejection close to the second injection site strengthens our observation. This case suggests that if the same dose of subtenon steroid is divided and injected into different quadrants, the short diffusion distance may engage the immune cells equally in all quadrants and give the graft a fair chance of survival. In conclusion, for corneal graft rejection, administration of triamcinolone in small amounts in multiple quadrants around the cornea may be a safe and effective way of controlling rejection. This is a single observational case, and further studies are warranted.

\section{Acknowledgment}

We would like to thank the Scientific Communication Group, University of Arkansas for Medical Sciences, Little Rock, AR, USA, for their assistance in editing. This study was partially supported by a fund from the Martha Wood Bentley Endowed Chair in Ophthalmology.

\section{Statement of Ethics}

No Institutional Review Board approval was required. The patient and family were informed, and a consent form was obtained and signed prior to writing the case report. Consent from the patient was taken for publication.

\section{Disclosure Statement}

The authors declare that there are no conflicts of interest. 
Goyal and Uwaydat: Multiquadrant Subtenon Triamcinolone Injection for Acute Corneal Graft Rejection: A Case Report

\section{Funding Sources}

This research was supported in part by the Department of Ophthalmology, Harvey \& Bernice Jones Eye Institute, UAMS and Research to Prevent Blindness.

\section{Author Contributions}

Both authors (S.G., S.H.U.) participated in patient care and writing of the report.

\section{References}

1 Lam H, Dana MR: Corneal graft rejection. Int Ophthalmol Clin 2009;49:31-41.

2 Shapiro MB, Krachmer JH: Rejection; in Brightbill FS (ed): Corneal Surgery, Theory, Technique and Tissues. St Louis, CV Mosby Company, 1997, pp 254-268.

-3 Dastjerdi MH, Saban DR, Okanobo A, Nallasamy N, Sadrai Z, Chauhan SK, Hajrasouliha AR, Dana R: Effects of topical and subconjunctival bevacizumab in high-risk corneal transplant survival. Invest Ophthalmol Vis Sci 2010;51:2411-2417.

4 Dana MR, Qian Y, Hamrah P: Twenty-five-year panorama of corneal immunology: emerging concepts in the immunopathogenesis of microbial keratitis, peripheral ulcerative keratitis, and corneal transplant rejection. Cornea 2000;19:625-643.

5 Panda A, Vanathi M, Kumar A, Dash Y, Priya S: Corneal graft rejection. Surv Ophthalmol 2007;52:375396.

-6 Arentsen JJ: Corneal transplant allograft reaction: possible predisposing factors. Trans Am Ophthalmol Soc 1983;81:361-402.

7 Alldredge OC, Krachmer JH: Clinical types of corneal transplant rejection. Their manifestations, frequency, preoperative correlates, and treatment. Arch Ophthalmol 1981;99:599-604.

8 Qazi Y, Hamrah P: Corneal allograft rejection: immunopathogenesis to therapeutics. J Clin Cell Immunol 2013;(Suppl 9):pii 006.

-9 Meyer PA, Watson PG, Franks W, Dubord P: "Pulsed" immunosuppressive therapy in the treatment of immunologically induced corneal and scleral disease. Eye (Lond) 1987;1(Pt 4):487-495.

$\checkmark 10$ Costa DC, de Castro RS, Kara-Jose N: Case-control study of subconjunctival triamcinolone acetonide injection vs intravenous methylprednisolone pulse in the treatment of endothelial corneal allograft rejection. Eye (Lond) 2009;23:708-714.

-11 Kovacs K, Wagley S, Quirk MT, Ceron OM, Silva PA, Singh RJ, Gukasyan HJ, Arroyo JG: Pharmacokinetic study of vitreous and serum concentrations of triamcinolone acetonide after posterior sub-tenon's injection. Am J Ophthalmol 2012;153:939-948.

12 Nan K, Sun S, Li Y, Qu J, Li G, Luo L, Chen H, Cheng L: Characterisation of systemic and ocular drug level of triamcinolone acetonide following a single sub-Tenon injection. Br J Ophthalmol 2010;94:654-658.

13 Zaka-ur-Rab S, Mahmood S, Shukla M, Zakir SM, Khan BA, Owais M: Systemic absorption of triamcinolone acetonide after posterior sub-Tenon injection. Am J Ophthalmol 2009;148:414-419.

Sami H. Uwaydat is the co-author. 
Case Reports in
Ophthalmology

Case Rep Ophthalmol 2017;8:308-313

DOI: $10.1159 / 000477202$

(c) 2017 The Author(s). Published by S. Karger AG, Basel www.karger.com/cop

Goyal and Uwaydat: Multiquadrant Subtenon Triamcinolone Injection for Acute Corneal Graft Rejection: A Case Report

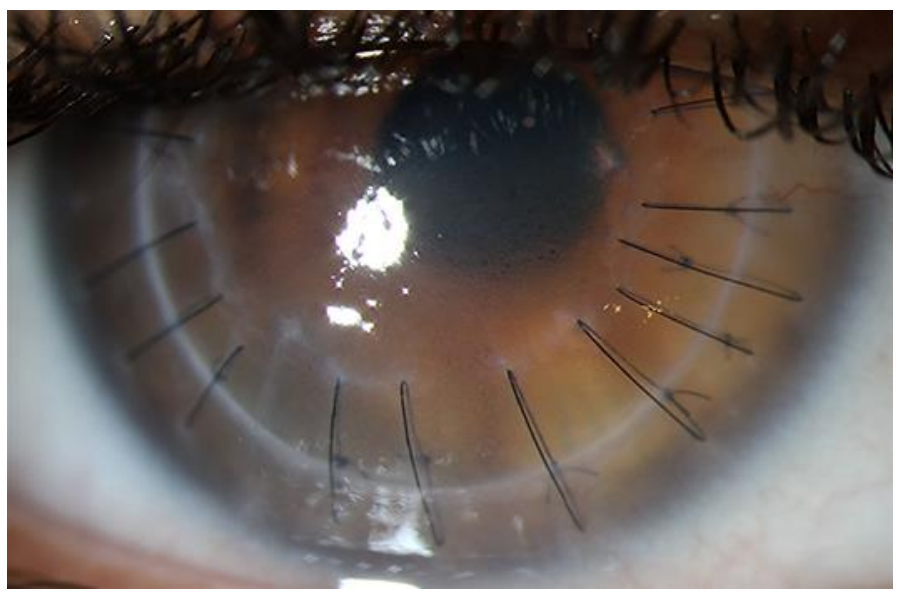

Fig. 1. Slit-lamp photograph of the right cornea shows endothelial rejection with diffuse epithelial and stromal edema, Descemet membrane fold, and an incomplete Khodadoust line.

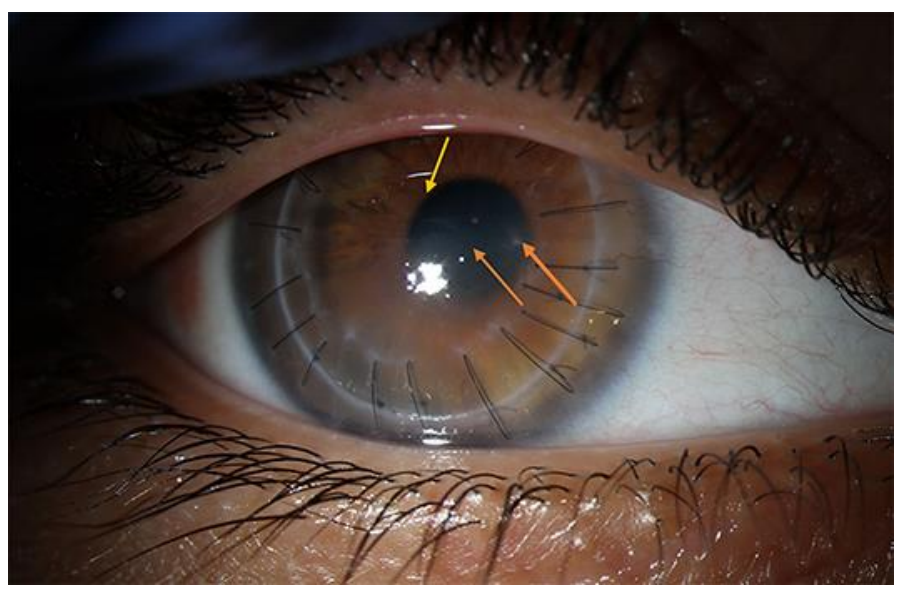

Fig. 2. Slit-lamp photograph of the right cornea 1 week after the initial subtenon injection in the superotemporal quadrant shows clearing (yellow arrow) of the superior half of the cornea. The inferior half shows corneal haze and a Khodadoust line (orange arrows). 
Case Reports in
Ophthalmology

Case Rep Ophthalmol 2017;8:308-313

(c) 2017 The Author(s). Published by S. Karger AG, Basel www.karger.com/cop

Goyal and Uwaydat: Multiquadrant Subtenon Triamcinolone Injection for Acute Corneal Graft Rejection: A Case Report

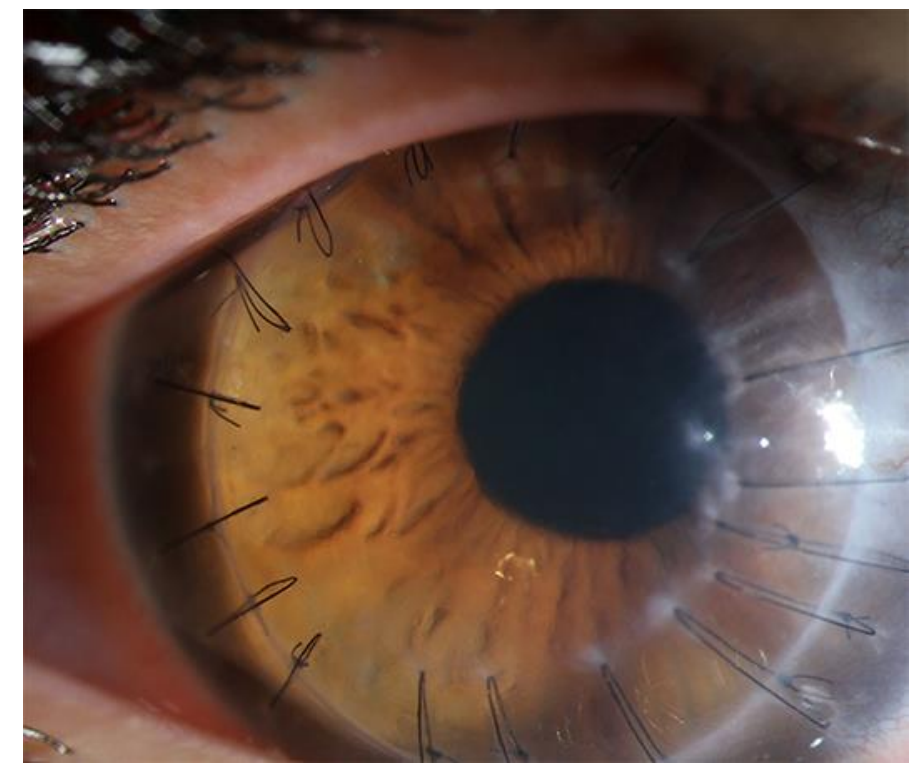

Fig. 3. Slit-lamp photograph of the right cornea 4 days after the second subtenon injection shows clearing of the entire corneal graft. 